\title{
Mediating Role of Job Satisfaction in the Relationship Between Organizational Support and Job Performance
}

\author{
Dilli Raj Sharma, Gangaram Biswakarma \\ Faculty of Management, Tribhuvan University, Kathmandu, Nepal \\ Email address: \\ dr7sharma@yahoo.com (D. R. Sharma),drgrbiswa@gmail.com (G. Biswakarma)

\section{To cite this article:} \\ Dilli Raj Sharma, Gangaram Biswakarma, Mediating Role of Job Satisfaction in the Relationship Between Organizational Support and Job \\ Performance. European Business \& Management. Vol. 6, No. 4, 2020, pp. 84-94. doi: 10.11648/j.ebm.20200604.13
}

Received: July 8, 2020; Accepted: July 25, 2020; Published: August 18, 2020

\begin{abstract}
Organizational support is a vital component providing help to employees to perform, however, the support meant to be meaningful and make individual satisfied with the job. It becomes more specific in the hospitality sector, especially hotel industry being a service sector, in which the performance of the employees is directly linked to the customers satisfaction. Subsequently for business performance and sustainability. In this view, this study aims to examining the interlinkage of perceived organizational support, perceived job satisfaction and perceived job performance. In addition, it investigated the mediating effect of perceived job satisfaction to relationship of perceived organizational support and perceived job performance. This study adopts a quantitative approach and a sample of 200 hotel employees were approached, out of which 158 employees responded. Results indicates that perceived organizational support is correlated with perceived job satisfaction and perceived job performance. It suggests job satisfaction mediated the effect of perceived organizational support on perceived job performance. The study findings presented concrete evidence that perceived organizational support and perceived job performance can be strengthen when employee perceived a satisfaction with their job. Thus, perceived organizational support can strongly relate with achieving higher level of perceived job performance in hotel industry with mediations of perceived job satisfaction. The finding of current study can help administrators, particularly in hotel industry to find ways to use organizational support to increase job performance.
\end{abstract}

Keywords: Perceived Organizational Support, Perceived Job Satisfaction, Perceived Job Performance, Nepali Hotel Industry

\section{Introduction}

Employee respond and perform better in alignment of the objectives of the organization when employee feel that their organization attends to their welfare. The employees therefore help the organization reach its objectives to save the source based on exchange norm [1]. Likewise, working environment for employee is resulted out of organizational support and thus resulted in job satisfaction, job performance and exerts an important influence on organizational performance. Job satisfaction and its correlates have received considerable attention in the western as well as non-western literature. It is because of job satisfaction remains a leading construct that divines the workforce behavior towards their organization. Substantially, with these assumptions, the purpose of this paper is to confirm the relationship of Perceived Organizational Support (POS), Perceived Job
Satisfaction (PJS) and Perceived Job Performance (PJP). It is also to identify the mediating role of Perceived Job Satisfaction between Perceived Organizational Support (POS) and Perceived Job Performance (PJP). Why Nepalese hotel industry that caters the need of international tourist? The answer is simple, such investigations are particularly important for a country like Nepal, where the Travel, Tourism and Hospitality Industry/Sector contributes $6.7 \%$ of GDP and providing employment of $6.9 \%$ of the total employment in the country and $30.8 \%$ of total export [2]. This paper targets both academicians and practitioners in Nepalese setting. As an academician, it will facilitate the understanding of the potential relationship between POS, PJS and PJP and the mediating role of PJP in between. Reflecting the relationship and mediating role of these variables, a practitioner can have the knowledge to which components to draw on for attention. They may know the effects of POS, PJS and PJP and 
consequently, they make themselves armed to combat these effects in Nepalese Hotel Industry that cater the need of international customers.

\section{Research Objectives}

This research aims to (i) investigate the relationship between Employees' Perceived Organizational Support (POS), and Employees' Perceived Job Performance (PJP) and (ii) examine the mediating effect of Employees' Perceived Job Satisfaction (PJS) between Employees' Perceived Organizational Support (POS), and Employees' Perceived Job Performance (PJP).

\section{Synthesis of Perceived Organizational Support, Job Satisfaction, and Job Performance - Brief Review}

Research indicates that companies with an excellent customer service record reported a $72 \%$ increase in profit per employee, compared to similar organizations that have demonstrated poor customer service; it is also five times costlier to attract new customers than to retain existing customers [3]. Bitner [4] also supported the notion that employee and customer responses to the firm environment influence the social interaction between them. In similar manner, job performance has been shown to be the best method for achieving better hotel service, productivity, and efficiency as well as improving guest satisfaction [5].

\subsection{Perceived Organizational Support and Perceived Job Performance}

POS refers to "the extent to which the organization values [employees'] contributions and cares about their well-being" [6]. The idea of Perceived Organizational Support was first introduced officially by Eizenberg in an article in organizational literature in 1986 [1]. There are several existing studies that have examined the relationship between Perceived Organizational Support and various kinds of work performance [7]. Perceived Organizational Support captures an employee's beliefs concerning the extent to which the organization values (employees') general contributions made on the organization's behalf and cares for their well-being [6, 8]. Perceived Organizational Support can have direct and indirect effect on employee behavior and the relation between them [1]. Na-Nan, Saribut and Sanamthong [9] study found that perceived environmental support and knowledge sharing positively influenced employee job performance of 344 admins working at SMEs in Central Thailand. Xiu, Dauner and McIntosh [10] in a study of 297 employees working at a public university in the US Midwest showed a result that employees' perceptions of organizational support for employee health positively related to both turnover intention and job performance. A study by $\mathrm{Du}$ et al. [11] of 594 employees in 3 manufacturing companies in Northeast China demonstrated the direct positive influence of perceived organizational support on in- role performance. Byrne and Hochwarter [12] found that the relationship between perceived organizational support and Job performance. Biswakarma [13] found a significant relationship between perceived job performance and perceived organizational support, and mentioned that the critical role in the employees' performance, they are to be sufficiently supported by the organization. Likewise, the studies of Burmeister and Deller [14], Yaakobi and Weisberg [15] proposed perceived environmental support and knowledge sharing as the main factors which enhanced effective employee job performance. Armeli, Eisenberger, Fasolo, and Lynch [16] studied patrol officers in USA with high socio-emotional needs, found that there was generally a positive relationship between Perceived Organizational Support and performance. Perceived Organizational Support is the extent to which employees perceive that the organization values their contributions and cares about their well-being [17]. Perceived Organizational Support may be encouraged by employees' tendency to ascribe human-like traits or characteristics to organizations [6]. Positive relationship between Perceived Organizational Support and work-related outcomes has been found in [16]. Likewise, Perceived Organizational Support was found positively related to evaluative and objective measures of performance in standard job activities $[16,6]$. In other studies, like Settoon, Bennett, and Liden [18] and Wayne, Shore, and Liden [19], it was found no relationship between Perceived Organizational Support and work performance using structural equation modeling. The analysis previous literature like Guan, Sun, Hou, Zhao, \& Luan [17] indicated that the relationship between Perceived Organizational Support and Perceived Job Performance was mediated by job satisfaction. Given past empirical evidence and arguments, it is believed that POS is linked to job performance.

\subsection{Perceived Organizational Support and Perceived Job Satisfaction}

Perceived Organizational Support is regarded as an exchange relationship between organization and employees based on organization support theory [6]. In recent study of Maan et al. [20] considering 936 employees working in various manufacturing and service sectors found that the positive association between Perceived Organizational Support and job satisfaction. Likewise, Karaalioğlu and Karabulut [21] conducted in energy sector found that perception of employees of organizational support has a direct positive influence on their job satisfaction. As such studies like Alcover et al. [22], Khan and Chandrakar [23] indicated the perceived organizational support is known to be positively related with job satisfaction. Bogler and Nir [24] in the study of 2,565 teachers affiliated with 153 Israeli elementary schools found that teachers who contemplate their school a place that values their contribution and cares about their well-being are more likely to be satisfied. Ahmad and Yekta [25], Burke and Greenglass [26], Hassan, Hassan, and Shoaib [27], Guan, Sun, Hou, Zhao, and Luan [17] have shown that Perceived Organizational Support was positively associated with levels of Perceived Job 
Satisfacton and Perceived Organizational Support has been proved to influence on employees' satisfaction. Consistent with past empirical findings, the theory of reasoned action lends theoretical rationale for why Perceived Organizational Support is positively linked to job satisfaction. The object of interest is the job, then only job-related beliefs will predict job-related attitudes (e.g., job satisfaction). To determine if these requirements are met in the relationships between Perceived Organizational Support and job satisfaction, we need to examine the definition of Perceived Organizational Support [28]. Thus, it appears that Perceived Organizational Support carries perceptions about both the organization's support of the employee as a person as well as the importance of the job performed by the employee, and would therefore impact job-related attitudes (i.e., job satisfaction) [28].

\subsection{Perceived Job Satisfaction and Perceived Job Performance}

Job satisfaction has been defined as the "positive emotional state resulting from the appraisal of one's job" [29, cited in 30]. The relationship between job satisfaction and job performance is not new in the psychology literature [30]. The idea that job satisfaction leads to better performance is supported by Vroom's [31] work which is based on the notion that performance is natural product of satisfying the needs of employees [32]. Research examining the relationship between job satisfaction and job performance has been conducted since at least as early as 1945 and methodology utilized has varied greatly [32]. The close relationship between job satisfaction and job performance is not something that has arisen recently addressed Argyris [33], Gross and Etzioni [34] cited in Platisa, Reklitisb, and Zimerasc [35]. These studies establish the idea of satisfied employees are more productive. Recent study of Karaalioğlu and Karabulut [21] study that was conducted in energy sector found that job satisfaction has a significant positive influence on job performance. As such studies like Wu et al. [36], job satisfaction is known to be positively related with job performance. Chao et al. [37] in a study of 344 healthcare employees working in a hospital in Taiwan revealed that turnover intention and job performance are affected positively, while positive effect found of job satisfaction on job performance. Several previous studies Judge et al. [38], Hanan [39], Kahya [40], Pugno and Depedri [30], and Platisa, Reklitisb, and Zimerasc [35] draws main conclusion that there is correlation between job satisfaction and job performance is positive and significant. However, there are contradictory perspectives on the relationship between job satisfaction and job performance. Keaveney and Nelson [41] and Ravindran [42] found no significant correlation between job satisfaction and job performance.

\subsection{Mediating Role of Perceived Job Satisfaction}

In the study of Karaalioğlu and Karabulut [21] found that job satisfaction has a full mediator role on the relationship between perceived organizational support and job performance. As such in Muse and Stamper's [43] research.
Likewise, the study of Guan, Sun, Hou, Zhao, and Luan [17] signifies that Perceived Organizational Support influenced job performance indirectly through job satisfaction. Our position that job satisfaction functions as a mediator within the nomological network has seldom been explicitly articulated in the organizational literature [28]. Social exchange theory suggests that employees engage in positive or negative behaviors toward the organization only in response to positive or negative actions that are seen to originate from the organization [28]. This suggests that job satisfaction mediates the relationship between actual organizational support and workplace behaviors [28].

\subsection{Research Gap}

Most of the research in international arena has covered or focused, Perceived Organizational Support, Perceived Job Satisfaction as determinants of Perceived Job Performance separately. However, to the best of author's knowledge, few studies focused on employee Perceived Organizational Support, Perceived Job Satisfaction and Perceived Job Performance, with understanding role Perceived Job Satisfaction in the past. Specially, in Nepalese context very limited studies have been conducted to empirically support the relationship of Perceived Organizational Support, Perceived Job Satisfaction and Perceived Job Performance, especially the hotel industry. Therefore, the present study would be a valuable attempt to plug the gap in this area.

\section{Research Framework and Hypotheses}

Based on literature review, the relationship of Perceived Organizational Support, Perceived Job Satisfaction and Perceived Job Performance seen under the proposed framework in Figure 1, the following hypotheses were advanced to identify the relationship of Perceived Organizational Support, Perceived Job Satisfaction and Perceived Job Performance.

H1: POS has significant positive direct effect on PJP.

H2: POS has significant positive direct effect on PJS.

H3: PJS has significant positive direct effect on PJP.

H4: PJS mediates the influence of POS on PJP.

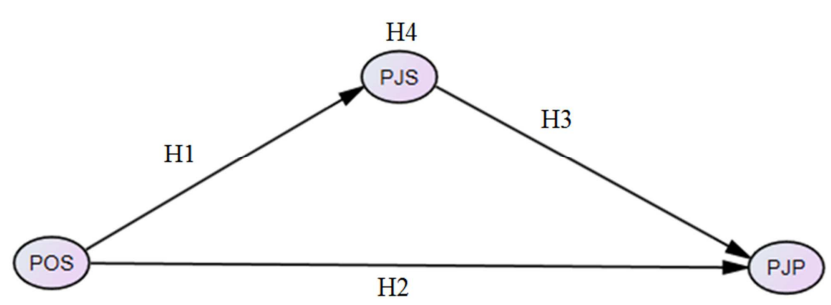

Figure 1. Conceptual Framework for the study.

\section{Research Methodology}

This study is based on quantitative approach towards descriptive and casual research design. The descriptive research design was used for answering the present situation of Perceived Organizational Support, Perceived Job 
Satisfaction and Perceived Job Performance in Nepalese Hotel Industry. Similarly, the need of explanatory casual research design needed and reflects to test the relationship and impact of independent variables over the dependent variable in the study. A sample of 200 employees working in different hotels in Kathmandu, Nepal were approached for the study. For the reliability of perception of the employee towards their respective organizations, employee having at least six months of working experience considered as valid sample. The employee's samples comprise of star category hotels in Kathmandu Valley. The data was collected from these hotels with convenience sampling, in which 200 questionnaires for employees were distributed out of which 158 number of employees responded and were in the position of utilization. The response rate was $79 \%$. The detail list of sample collection can be seen at Table 1 .

Table 1. List of samples from the hotel industry.

\begin{tabular}{lll}
\hline Employees & $\mathbf{n}$ & $\mathbf{\%}$ \\
\hline Hotel & 8 & 5.06 \\
\hline Airport Hotel & 9 & 5.70 \\
Ambassadors & 10 & 6.33 \\
Everest Hotel & 11 & 6.96 \\
Hotel Annapurna & 7 & 4.43 \\
Hotel Manang Thamel & 8 & 5.06 \\
Hotel Shanker & 9 & 5.70 \\
Hotel Vaishali & 14 & 8.86 \\
Hyatt Regency & 15 & 9.49 \\
Hotel Malla & 12 & 7.59 \\
Marcopolo Business & 11 & 6.96 \\
Radission & 17 & 10.76 \\
Shangri-la Hotel & 13 & 8.23 \\
Soaltee & 14 & 8.86 \\
Yak and Yeti & 158 & 100 \\
N & & \\
\hline
\end{tabular}

\subsection{Conceptual Model and Instrumentation}

The conceptual framework for this study constitutes of three construct- Perceived Organization Support (POS), Perceived Job Satisfaction (PJS) and Perceived Job Performance (PJP). Measures designed with Perceived Organizational Support (POS) scale Rhoades et al., (2001) with eight items of the POS scale in 5-point Likert scale. Perceived Job Performance (PJS) scale is adopted from Bowra et al. [44] with three items in 5-point Likert scale. Perceived Job Satisfaction scale was self-developed with three items scale in 5-point Likert scale.

\subsection{Analytical Strategy}

First of all, the variables were put into the exploratory factor analysis (EFA) to ensure the factor loading of the items, whether the items are loaded within their particular latent variables. Secondly, to illustrate that all items evaluating the research variables, confirmatory factor Analysis (CFA) was performed. It is for examining the unidimensionality of the construct of the latent variables. Next, the construct validity and reliability were examined. Finally, the path analysis was examined to test the hypothesis to identify significant direct and indirect effect of variables. The CFA and Path analysis was performed using AMOS v23., and other descriptive analysis was performed with SPSS v23.

\section{Results}

\subsection{Demographic Profile of Respondents}

Analysis of demographic variables of employees, the results indicate that the majority of employee respondents were male $58.9 \%$. $(n=93)$, female employees constituted of $41.1 \%(n=65)$. The employees' sample constituted of $58.2 \%$ $(n=92)$ in age group of 21 to 30 years. Maximum of the employees were single with $58.9 \%(n=93)$. The results in detail is placed in Table 2 .

Table 2. Profile of the respondents.

\begin{tabular}{llllll}
\hline Employees & \multicolumn{5}{c}{ Employees } \\
\hline Gender & $\boldsymbol{n}$ & $\boldsymbol{\%}$ & Income & $\boldsymbol{n}$ & $\boldsymbol{\%}$ \\
\hline Female & 65 & 41.1 & Below 20000 & 26 & 17.1 \\
Male & 93 & 58.9 & $20000-30000$ & 68 & 44.7 \\
Total & 158 & 100 & $30000-40000$ & 39 & 25.7 \\
Marital Status & $n$ & $\%$ & 40000 and above & 19 & 12.5 \\
Single & 93 & 58.9 & Total & 152 & 100 \\
Married & 62 & 39.2 & & & \\
Divorced/widowed & 3 & 1.9 & & & \\
Total & 158 & 100 & & & \\
Age group in yrs. & $n$ & $\%$ & Employees: N=158 & \\
Below 20 & 23 & 14.6 & & & \\
21 -30 & 92 & 58.2 & & & \\
$31-40$ & 38 & 24.1 & & & \\
40 and above & 5 & 3.2 & & & \\
\hline
\end{tabular}

\subsection{Exploratory Factor Analysis}

Before analyzing the model with Confirmatory Factor Analysis and Path analysis, the factor loading of latent variables was confirmed by exploratory factor analysis (EFA) with Principal Component Analysis, component rotated with Varimax with Kaiser Normalization. The respective latent variables and items were confirmed in the same factors in measurement. Table 3, output presents figures relating to the test for sampling adequacy (KMO) and the Bartlett's test of sphericity. KMO statistics was 0.869 , which was above the lower threshold of 0.5. Likewise, the Bartlett's test of sphericity suggests that, with the overall statistical significance of the correlations among the observed variables, can perform factor analysis. The Chi-square value (1493.247) is statistically significant at $(\mathrm{p}=0.001)$, place in Table 3 . The factors are extracted with 1 or higher eigenvalues, as suggested by Guttman, considers factors with an eigenvalue greater than one as common factor (Nunnally, 1978). In the event of that, total variance as explained by the three factors was $71.52 \%$ cumulative variance. The factor loading of the four factors is placed in Annexure-1.

Table 3. KMO and Bartlett's Test.

\begin{tabular}{lll}
\hline Kaiser-Meyer-Olkin & & $\mathbf{. 8 6 9}$ \\
\hline \multirow{3}{*}{ Bartlett's Test of Sphericity } & Approx. Chi-Square & 1493.247 \\
& df & 91 \\
& Sig. & .001 \\
\hline
\end{tabular}




\subsection{Confirmatory Factor Analysis}

Erstwhile to examining the relations among the variables, the subscale or the construct of latent variables was analyzed with confirmatory factor analysis to establish its unidimensionality of the whole construct (questionnaire items). Forthwith, a certain degree of model fit is necessary before the testing of the general model is done [45]. Henceforth, CFA model fit test was done. The results of the CFA are placed in table 4 and the structural model with factor loading can be seen at figure 2. At first, the filtration of the model fit items was done with the factor loading. There should be at least 3 items with significant loadings $(>0.30)$ [46]. Under the circumstance, to be more precise all the items had factor loading higher than 0.5 are kept. Congruently, on the basis of the modification indices, the model fit has been achieved. Modification indices suggested remedies to discrepancies between the proposed and estimated model. Standard residual covariance was tested for significantly decreasing the model fit. Fixing the model fit, few items in latent variables were covariate. Items like POS3, POS5 and POS8 in POS latent variable were covariate, like wise POS4 was also deleted due to higher Standardized Residual Covariance in the latent variable-POS. Model fit indices appears quite good. Results from the estimation from the model yielded overall fit indices for the CFA model, which were acceptable, with $\chi 2 / \mathrm{df}=102.347, \mathrm{CMIN} / \mathrm{Df}=1.706$, $\mathrm{p}=0.001$. The measurement model has a good fit with the data based on assessment criteria such as GFI, CFI, TLI, RMSEA [47, 48]. Therefore, RMSEA $=0.068(<0.08$ [49]; $<0.05$ [50]; $<0.05$ [51]). In like manner, GFI $=0.91, \mathrm{CFI}=0.969$ indicating model Good Fit, which is also within the upper threshold of $>.95$ [51]. PCLOSE $=0.093(>.05$ [51]). AGFI $=.863(>.80$ $[51]) . \mathrm{PCFI}=0.746(>0.50[45]) . \mathrm{IFI}=0.97, \mathrm{TLI}=0.96$ which is also within the threshold $(>0.90[52]), \mathrm{PGFI}=0.863(>0.50$ [45]). At least three indices must be fitted well to determine the model fit [53]. The summary of model fit indices is placed in Table 4. It can be concluded with the help of indices that the four designed scales had good unidimensionality. After obtaining evidence of the unidimensionality of the designed scales, reliability and validity was ascertained.

Table 4. Summary of model fit indices for Structural model.

\begin{tabular}{ll}
\hline Measures & Observed value of the model \\
\hline$\chi^{2}$ & 102.347 \\
$\mathrm{p}$ & 0.001 \\
$\mathrm{df}$ & 60 \\
CMIN/df & 1.706 \\
RMSEA & 0.068 \\
PCLOSE & 0.093 \\
GFI & 0.91 \\
CFI & 0.969 \\
AGFI & 0.863 \\
PCFI & 0.746 \\
IFI & 0.97 \\
TLI & 0.96 \\
PGFI & 0.863 \\
\hline
\end{tabular}

$\chi 2=$ Chi-Square; $\mathrm{p}$ - value for the model, Df=Degree of freedom; RMSEA=Root mean square error of approximation fit index; PCLOSE=p of Close Fit, GFI=goodness of fit index; $\mathrm{CFI}=$ Comparative fit index; $\mathrm{AGFI}=\mathrm{Absolute}$ goodness of fit index; PCFI=Parsimony goodness of fit index; IFI=Incremental fit index; TLI=Tucker-Lewis index; PGFI=Parsimony goodness of fit index.

Figure 2 presents the CFA of latent variable construct (Proposed and Final Model of Construction).

\subsection{Reliability, Convergent Validity and Discriminant Validity}

The result of the reliability and validity is presented in table 5. Reliability was analyzed with CA. FL, CR and AVE were used to test convergent validity. Likewise, MSV and ASV were used to test the discriminant validity of the measurement model. Reliability with the indices of CR $>0.7$, Convergent Validity with the indices of CR $>$ AVE, AVE $>.5$, Discriminant Validity with the indices of MSV $<$ AVE, ASV $<$ AVE (threshold of Hair et al. [53]). This is a satisfactory level of internal consistency of the measures and there exist some common points of convergence [53]. This indicates measurement model is according to the assumptions which were originally made.

Table 5. Reliability, convergent validity and discriminate.

\begin{tabular}{|c|c|c|c|c|c|c|c|}
\hline Constructs & Items & Factor Loadings & Cronbach's Alpha & CR & AVE & MSV & ASV \\
\hline \multirow{7}{*}{ POS } & POS1 & 0.88 & \multirow{7}{*}{.929} & \multirow{7}{*}{.928} & \multirow{7}{*}{.62} & \multirow{7}{*}{.4} & \multirow{7}{*}{.18} \\
\hline & POS2 & 0.74 & & & & & \\
\hline & POS3 & 0.70 & & & & & \\
\hline & POS4 & 0.58 & & & & & \\
\hline & POS5 & 0.91 & & & & & \\
\hline & POS6 & 0.67 & & & & & \\
\hline & POS8 & 0.78 & & & & & \\
\hline \multirow{3}{*}{ PJP } & PJP1 & 0.81 & \multirow{3}{*}{.752} & \multirow{4}{*}{.760} & \multirow{4}{*}{.52} & \multirow{3}{*}{.2} & \multirow{3}{*}{.32} \\
\hline & PJP2 & 0.74 & & & & & \\
\hline & PJP3 & 0.59 & & & & & \\
\hline \multirow{3}{*}{ PJS } & $J S 1$ & 0.78 & \multirow{3}{*}{.852} & & & \multirow{3}{*}{.4} & \multirow{3}{*}{.20} \\
\hline & $J S 2$ & 0.83 & & \multirow[t]{2}{*}{.854} & \multirow[t]{2}{*}{.66} & & \\
\hline & $J S 3$ & 0.83 & & & & & \\
\hline
\end{tabular}

Composite Reliability (CR), Average Variance Extracted (AVE), Maximum Shared Squared Variance (MSV), and Average Shared Squared Variance (ASV). POS: Perceived Organization Support; PJP: Perceived Job Perception; JS: Job Satisfaction; CS: Customer Satisfaction. 

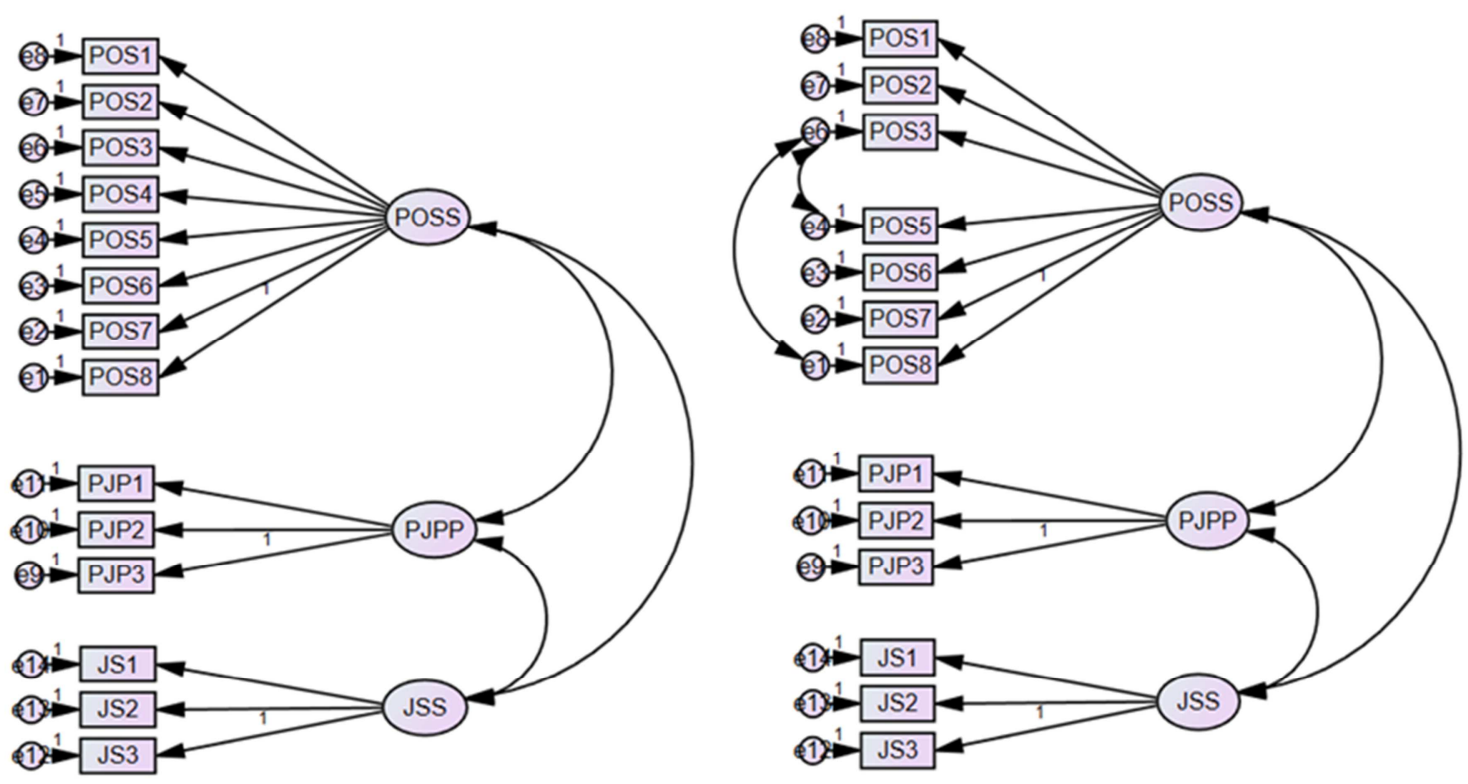

Figure 2. Proposed and final model of construct.

\section{Status of Perceived Organizational Support, Perceived Job Satisfaction and Perceived Job Performance in Nepalese Hotel Industry}

The present level of perception on Organizational Support, Job Satisfaction, and Job Performance of employees can be measured with the results which is placed in table 6. There is a moderate level of POS, PJS and PJP in hotel industries employees, it can be interpreted with mean value of $3.59 \quad(\mathrm{SD}=0.56), \quad 3.5 \quad(\mathrm{SD}=.801)$ and 3.72 $(\mathrm{SD}=.63698)$. The sampled organization strongly considers the goals and values of the employees $3.63(\mathrm{SD}=.61)$ along with forgiveness towards an honest mistake on employee part $3.63(\mathrm{SD}=.69)$. Employees perceived that their performance is better than that of their colleagues with mean value of $3.82(\mathrm{SD}=.88)$, and satisfied with their performance with a mean value of 3.67 ( $\mathrm{SD}=.795)$. Employees are satisfied with working conditions in the sampled organization $3.6(\mathrm{SD}=.954)$ and overall, they are satisfied with the kind of work they do $3.42 \mathrm{SD}=0.83$.

Table 6. Status of POS, PJS, and PJP - Descriptive Statistics.

\begin{tabular}{lll}
\hline Variables & Mean & Std. Deviation \\
\hline POS & 3.59 & 0.56 \\
PJS & 3.51 & 0.801 \\
PJP & 3.72 & 0.636 \\
CS & 3.61 & 0.78 \\
\hline
\end{tabular}

$\mathrm{N}=158$.

\section{Path analysis - Correlation and Impact Analysis}

Following the first step of measurement model testing, the second step of analyzing the structural models was performed to test the research hypotheses which is presented in model Figure 3. Path analysis was performed by using AMOS 23v. The results showed that, the research model has near good fit to the data according to indices which were recommended by SEM literature Hair et al [53] and Bollen [54]): with $\chi 2 / \mathrm{df}=193.242 / 0.001, \mathrm{CMIN} / \mathrm{Df}=2.11, \mathrm{p}=0.001 . \mathrm{RMSEA}=0.011$ In like manner, GFI $=0.956, \mathrm{CFI}=0.905, \mathrm{PCLOSE}=0.053$, $\mathrm{AGFI}=889, \mathrm{PCFI}=0.719, \mathrm{IFI}=0.906, \mathrm{TLI}=0.980, \mathrm{PGFI}=0.583$.

\subsection{Correlation Analysis}

Correlation between all the measures are presented in Table 7. The results show that there is a comparatively moderate correlation between POS and PJS; PJS and PJP. Similarly, comparatively moderate to strong correlation between POS and PJP. As expected, a positive moderate to strong relationship between the variables.

Table 7. Correlations matrix of POS, PJS and PJP.

\begin{tabular}{lllll}
\hline Variables & & $\boldsymbol{P O S}$ & $\boldsymbol{P J S}$ & $\boldsymbol{P J P}$ \\
\hline POS & $\mathrm{r}$ & 1 & $.303^{*}$ & $.568^{* *}$ \\
PJS & $\mathrm{r}$ & $.303^{*}$ & 1 & $.331^{* *}$ \\
PJP & $\mathrm{r}$ & $.568^{* *}$ & $.331^{* *}$ & 1 \\
\hline
\end{tabular}

**. Correlation is significant at the 0.01 level (2-tailed). *. Correlation is significant at the 0.05 level (2-tailed).

\subsection{Impact Analysis}

The path analysis of the model results under the Regression Weights heading the standardized loadings along with standard errors and $\mathrm{p}$-values are presented in table 8 .

All of the unconstrained estimates are significant expect the POS -> PJP. The Standardized Regression Weights can be interpreted as the correlation and influence between the observed variable and the corresponding common factor. Three construct factors (POS->PJP, and PJS->PJP) are 
significant at the 0.01 level and one construct factors (POS$>$ PJS) at the 0.05 level. The Standardized Regression Weights is comparatively high in factor construct of POS$>$ PJP than other constructs.

As above, the regression weight had made it clear understanding of impact of POS on PJP \& PJS, and PJS on PJP. The results show POS positively affects the PJP ( $\beta=0.564, p<0.001)$, would cause the PJP to increase by
$56.4 \%$. Similarly, POS positively affects the PJS $(\beta=0.178$, $\mathrm{p}<0.05$ ), would cause the PJS to increase by $17.8 \%$. PJS positively affects the $P J P(\beta=0.333, p<0.01)$, would cause the PJP to increase by $33.3 \%$.

Hence, path analysis determined the theoretically based hypothesis. The hypotheses, $\mathrm{H} 1, \mathrm{H} 2$, and $\mathrm{H} 3$, were verified using the values (shown in the path diagram in figure 3 and table 8) and accepted.

Table 8. Standardized Regression Weights (SME Model).

\begin{tabular}{|c|c|c|c|c|c|}
\hline Hypothesis & Exogenous & Endogenous & Estimate (Standardized) & S. E. & $\mathbf{P}$ \\
\hline $\mathrm{H} 1$ & POS & PJP & 0.564 & 5.236 & $* * *$ \\
\hline $\mathrm{H} 2$ & POS & PJS & 0.178 & 1.989 & 0.047 \\
\hline $\mathrm{H} 3$ & PJS & PJP & 0.333 & 3.633 & $* * *$ \\
\hline & & & & & $\mathrm{R}^{2}=0.5$ \\
\hline
\end{tabular}

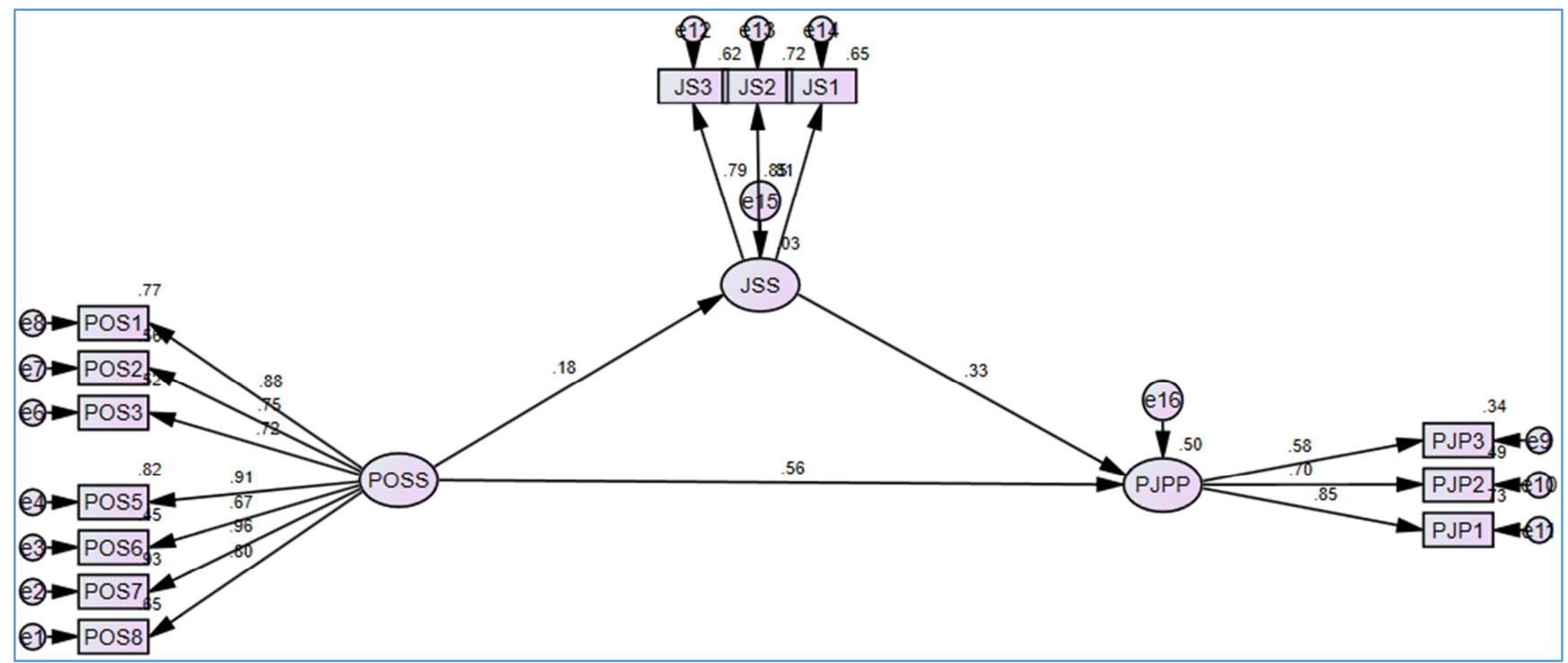

Figure 3. SEM- Path Analysis.

Table 9. Summary of Hypothesis test.

\begin{tabular}{ll}
\hline Hypotheses & Result \\
\hline H1: POS has significant positive direct effect on PJP & Accepted \\
H2: POS has significant positive direct effect on PJS & Accepted \\
H3: PJS has significant positive direct effect on PJP & Accepted \\
\hline
\end{tabular}

\subsection{Mediating Role Analysis}

The present model also analyzed the mediating role of PJS toward POS to PJP. The direct effect by the construct model was performed first and later the mediation effects were analyzed based on the respective hypothesis. The construct was mediation of PJS between POS and PJP. The mediation test was performed through SEM (path analysis) with bootstrapping. The bootstrap estimates presented were based on 2000 sample and Bias-corrected CI at $95 \%$. The result of mediation test is placed in table 10 . The result indicates that
PJS partially mediate effect of POS on PJP. Therefore, it is indicated that effect of POS on PJP is mediated by PJS of employees. The standardized indirect (mediated) effect of POS on PJP is 0.059 . That is, due to the indirect (mediated) effect of POS on PJP, when POS goes up by 1 standard deviation, PJP goes up by 0.059 standard deviations. This is in addition to any direct (unmediated) effect that POS may have on PJP. It signifies not only the importance of the employees' perception on organizational support towards their job performance, it too indicates the importance of job satisfaction towards employees' perception on organizational support and their job performance. The result of mediation test significantly tests the hypothesis. The hypotheses, H4, was verified using the values of direct beta without mediation, direct beta with mediation and indirect beta as shown in table. Hence, $\mathrm{H} 4$ is accepted, as there is a mediation relationship in between the variables under observation.

Table 10. Summary of Hypothesis testing to identify mediation.

\begin{tabular}{llllll}
\hline Hypothesis & Hypothesis & Direct Beta w/o Med & Direct Beta w/Med & Indirect Beta & Mediation type observed \\
\hline H4 & POS-PJS-PJP & $0.645^{* * *}$ & $0.564 * *$ & $0.059 * *$ & Partial \\
\hline
\end{tabular}

Note: bootstrap sample $=2000 ; * * * \mathrm{p}<.01, * * \mathrm{p}<0.05$, BC Confidence Interval $=95 \%$ 
Table 11. Summary of Hypothesis testing to identify mediation.

\begin{tabular}{ll}
\hline Hypotheses & Result \\
\hline H4: PJS will mediate the influence of POS on PJP & Accepted \\
\hline
\end{tabular}

\section{Discussion}

There are several studies that focused towards relationship between organizational support, job satisfaction and job performance, with inclusion of organizational commitment, self-efficacy and so on. However, few studies are based on purely examining the interaction of organizational support, job satisfaction and job performance directly in the hotel industry domain. Our results extend existing studies showing that the relationship between POS, PJS, and PJP in Nepalese hotel industry. Diverse samples of employees from the hotel industry in Nepal are used for the study. The empirical finding of this study reveals that POS is directly related to PJS and PJP. In this study, it was found that POS has significant positive direct effect on PJP, the finding is consistent with past empirical findings of $\mathrm{Na}-\mathrm{Nan}$, Saribut and Sanamthong [9], Xiu, Dauner and McIntosh [10], Du et al. [11], Byrne and Hochwarter [12], Biswakarma [13], Burmeister and Deller [14], Yaakobi and Weisberg [15], Wickramasinghe and Wickramasinghe [8], Hakkak, Gashti, and Nawaser [1], Guan, Sun, Hou, Zhao, and Luan [17], Armeli, Eisenberger, Fasolo, and Lynch [16], Eisenberger, Huntington, and Hutchison [6], where it was mentioned that the critical role in the employees' performance, they are to be sufficiently supported by the organization [13]. Burmeister and Deller [14], Yaakobi and Weisberg [15] concluded that perceived environmental support and knowledge sharing as the main factors which can heightened active job performance. However, it fails to support the study which advocate that there is no relationship between POS and PJP e.g., Bennett and Liden [18] and Wayne, Shore, and Liden [19].

Similarly, it is found that POS has significant positive direct effect on PJS, that provides empirical support for the studies like Maan et al. [20], Karaalioğlu and Karabulut [21], Alcover et al. [22], Khan and Chandrakar [23], Bogler and Nir [24], Eisenberger, Huntington, \& Hutchison [6], Ahmad and Yekta [25], Burke and Greenglass [26], Hassan, Hassan, and Shoaib [27] and Guan, Sun, Hou, Zhao and Luan [17], wherein they emphasized POS is known to be positively related with PJS. A positive role of POS on PJS is aligned with the previous studies. It is empirically support that when employees perceive that their organization care and support their contribution to the organization, and organization is conscious about the employee welfare and wellbeing, it results in greater job satisfaction.

Likewise, the study infers that PJS is significantly related to the PJP of the employees. The cause and effect determinants are still unclear and it cannot be assumed that satisfaction leads to high performance, or that high performers are necessarily satisfied with their jobs [55]. The empirical findings in this study showed that PJS has significant positive direct effect on PJP, this empirically supports studies like Karaalioğlu and Karabulut [21], Wu et al. [36], Chao et al. [37], Platisa, Reklitisb, and Zimerasc [35], Davar and Bala [32], Nabirye, Brown, Pryor and Marles [56], Pugno and Depedri [30], Kahya [40], Hanan [39], Judge et al. [38], Vroom [31], Argyris [33], Gross and Etzioni [34]. The previous studies emphasized on POS enhances positively influences PJP and PJS. Employees' abilities for tasks are not only significant for reciprocating resources that organizations invest in employees, but also enhances employee well-being [57]. However, this study did not replicate the findings of findings of Keaveney and Nelson [41] and Ravindran [42]. Therefore, it has been established that employee job satisfaction exerts an important influence on job performance.

Further, PJS has significantly mediates the effect of POS on PJP, this is alinged with the study of Karaalioğlu and Karabulut [21], Muse and Stamper's [43], Guan, Sun, Hou, Zhao and Luan [17] and Miao [28]. This study finding supports the previous studies notion that PJS has a full mediator role on the relationship between POS and PJP, however, a partial mediation is found in this study. This can be interpreted with the organizational support with mediation of job satisfaction can strongly relate with achieving higher level of job performance in hotel industry. That means PJP can be achieved at higher level with creating POS by improving PJS. It supports the findings of Guan, Sun, Hou, Zhao and Luan [17] that signifies that POS influenced job performance indirectly via job satisfaction. Thus, it may be concluded that the present study provides evidence that POS is correlated with PJS and PJP, with mediating effects of PJS towards the effect of POS on PJP.

\section{Conclusion}

This research contributes to the organizational behaviors and human resource management literature with an aim of examining the interlinkage of perceived organizational support, perceived job satisfaction and perceived job performance. In addition, with an investigation of mediating effect of perceived job satisfaction to relationship of perceived organizational support and perceived job performance. This current study provides a cohesive study model revealed the interconnection between perceived organizational support and perceived job performance through the mediating role of perceived job satisfaction.

The study findings presented concrete evidence that perceived organizational support and perceived job performance can be strengthen when employee perceived a satisfaction with their job. It can be meant that only support from the organization can implicate the performance, when employees perceived it is meaningfully contributing to their job satisfaction. Perceived job satisfaction is significant in the context of job performance with necessary and meaningful organizational support.

Therefore, hotel industry in Nepal, should begin proper initiatives towards creating an organizational employee supportive environment to increase the job satisfaction and employee job performance, so that, the ultimate goal of organization can be achieved. This will unquestionably help 
[15] Yaakobi, E., \& Weisberg, J. (2018). Individual, group and organizational efficacies in predicting performance. Personnel Review, 47 (2), 535-554.

[16] Armeli, S., Eisenberger, R., Fasolo, P., \& Lynch, P. (1998). Perceived Organizational Support and Police Performance: The Moderating Influence of Socioemotional Needs. Jounal of Applied Psychology, 83 (2), 288-297.

[17] Guan, X., Sun, T., Hou, Y., Zhao, L., \& Luan, Y.-Z. (2014). The relationship between job performance and perceived organizational support in faculty members at Chinese universities: a questionnaire survey. BMC Medical Education, 14 (50).

[18] Settoon, R., Bennett, N., \& Liden, R. (1996). Social exchange in organizations: perceived organizational support, leadermember exchange, and employee reciprocity. Journal of Applied Psychology, 81, 219-227.

[19] Wayne, S., Shore, 1., \& Liden, R. (1997). Perceived organizational support and leader-member exchange: a social exchange perspective. Academy of Management Journal, 40, 82-111.

[20] Maan, A. T., Abid, G., Butt, T. H., Ashfaq, F., \& Ahmed, S. (2020). Perceived organizational support and job satisfaction: a moderated mediation model of proactive personality and psychological empowerment. Future Business Journal, 6 (1), $1-12$.

[21] Karaalioğlu Z. F. \& Karabulut A. T. (2019), The Mediating Role of Job Satisfaction On The Relationship Between Perceived Organizational Support and Job Performance. Business \& Management Studies: An International Journal, 7 (2), 1022-1041.

[22] Alcover, C. M., Chambel, M. J., Fernández, J. J., \& Rodríguez, F. (2018). Perceived organizational support burnout satisfaction relationship in workers with disabilities: The moderation of family support. Scandinavian journal of psychology, 59 (4), 451-461.

[23] Khan, K. A. U. Z., \& Chandrakar, S. (2017). Perceived Organizational Support and Personality Dimensions as Predictors of Job Satisfaction. Indian Journal of Health and Wellbeing, 8 (1), 54-56.

[24] Bogler, R., \& Nir, A. E. (2012). The importance of teachers' perceived organizational support to job satisfaction. Journal of Educational Administration, 50 (3), 287-306.

[25] Ahmad, Z., \& Yekta, Z. (2010). Relationship between perceived organizational support, leadership behavior, and job satisfaction: An empirical study in Iran. Intangible Capital, 6 (2), 162-184.

[26] Burke, R., \& GREENGLASS, E. (2001). Hospital restructuring and nursing staff wellbeing: the role of perceived hospital and union support. Anxiety, Stress and Coping: An International Journal, 14, 93-115.

[27] Hassan, S., Hassan, M., \& Shoaib, M. (2014). Measuring the Impact of Perceived Organization Support, Psychological Empowerment and Rewards on Employees' Satisfaction: Testing the Mediating Impact of Employee Engagement. World Applied Sciences Journal, 30 (5), 652-660.

[28] Miao, R.-T. (2010). The Relationship between Perceived Organizational Support and Performance. IEEE.

[29] Locke, L. (1969). What is Job Satisfaction? rganizational
Behavior and Human Performance, 4, 309-336.

[30] Pugno, M., \& Depedri, S. (2009). Job performance and job satisfaction: an integrated survey. Discussion Paper No. 4, Universita Degli Studi Di Trent, Dipartimento di Economia.

[31] Vroom, V. (1964). Work and Motivation. New York: Wiley.

[32] Davar, S., \& Bala, R. (2012, Oct). Relationship between Job Satisfaction \& Job Performance: a Meta-analysis. The Indian Journal of Industrial Relations, 48 (2), 290-305.

[33] Argyris, C. (1964). Integrating the individual and the organization. New York: Wiley.

[34] Gross, E., \& Etzioni, A. (n. d.). Organizations in society. Englewood Cliffs, NJ: Prentice-Hall.

[35] Platisa, C., Reklitisb, P., \& Zimerasc, S. (2015). Relation between job satisfaction and job performance in healthcare services. Procedia - Social and Behavioral Sciences, 175, 480-487.

[36] Wu, C. H., Chen, I. S., \& Chen, J. C. (2017). A study into the impact of employee wellness and job satisfaction on job performance. International Journal of Organizational Innovation, 10 (2).

[37] Chao, M. C., Jou, R. C., Liao, C. C., \& Kuo, C. W. (2015). Workplace stress, job satisfaction, job performance, and turnover intention of health care workers in rural Taiwan. Asia Pacific Journal of Public Health, 27 (2), 1827-1836.

[38] Judge, T., Bono, J., Thoresen, C., \& Patton, G. (2001). The Job Satisfaction-Job Performance Relationship: A Qualitative and Quantitative Review. Psychological Bulletin, 127, 376-407.

[39] Hanan, A.-A. (2009). Factors affecting performance of hospital nurses in Riyadh Region, Saudi Arabia. International Journal of Health Care Quality Assurance, 22 (1), 40-54.

[40] Kahya, E. (2008). The effects of job performance on effectiveness. International Journal of Industrial Ergonomics, $39(1), 96-104$.

[41] Keaveney, S., \& Nelson, J. (1993). Coping with organizational Role Stress: Intrinsic Motivational Orientation, Perceived Role Benefits, and Psychological Withdrawal. Journal of the Academy of Marketing Science, 21, 113-24.

[42] Ravindran, C. (2007). Study of Factors Influencing the Work Output of Human Resource in Revised National Tuberculosis Control Program (RNTCP). Pulmon, 9 (3), 88-96.

[43] Muse, L. A., \& Stamper, C. L. (2007). Perceived organizational support: Evidence for a mediated association with work performance. Journal of Managerial Issues, 517535.

[44] Bowra, Z. A., Sharif, B. \&Niazi, M. K. 2011. Impact of human resource practices on employee perceived performance in banking sector of Pakistan. African Journal of Business Management. 6 (1). 323-332.

[45] Mulaik, S. A., \& James, L. R. (1995). Objectivity and reasoning in science and structural equation modeling. In $\mathrm{R}$. H. Hoyle (Ed.), Structural equation modeling: Concepts, issues, and applications (p. 118-137). Sage Publications, Inc.

[46] Suhr, D. (2012). Exploratory factor analysis with the world values survey. In Proceedings of the SAS Global Forum 2012 Conference. 
[47] Nejatian, H., Piaralal, S. K., Sentosa, I., and Bohari, A. M. (2011). The Influence of Customer Knowledge on CRM Performance of Malaysian ICT Companies: A Structural Equation Modeling Approach. International Journal of Business and Management, 6 (7), p. 181. [Online] www.ccsenet.org/ijbm, doi: 10.5539/ijbm.v6n7p181 Canadian Center of Science and Education (CCSE), [Accessed 22 Aug 2015].

[48] Bagozzi, R. P. and Yi, Y. (1988). On the evaluation of structural equation models. Journal of the Academy of Marketing Science. 16 (1). 74-94.

[49] Browne, M. W. \& Cudeck, R. (1993). Alternative ways of assessing model fit. In Bollen, K. A. \& Long, J. S. [Eds.] Testing structural equation models. Newbury Park, CA: Sage, 136-162.

[50] Steiger, J. H. (1989). EZPATH: A supplementary module for SYSTAT and SYGRAPH. Evanston, IL: SYSTAT.

[51] Hu, L., \& Bentler, P. M. (1999). Cutoff criteria for fit indexes in covariance structure analysis: Conventional criteria versus new alternatives. Structural Equation Modeling, 6, 1-55.
[52] Tucker, L. R., \& Lewis, C. (1973). A reliability coefficient for maximum likelihood factor analysis. Psychometrika, 38 (1), 110.

[53] Hair, J., Black, W., Babin, B., and Anderson, R. (2010). Multivariate data analysis. 7 th ed. NJ: Prentice-Hall.

[54] Bollen, K. A. (1989). Structural Equations with Latent Variables. John Wiley \& Sons.

[55] Euske, K. J., Jackson, D. W., \& Reif, W. E. (1980). Performance and satisfaction of bank managers. Journal of Bank Research, 11 (1), 36-42.

[56] Nabirye, R., Brown, K., Pryor, E., \& Marles, E. (2011). Occupational stress, job satisfaction and job performance among hospital nurses in Kampala, Uganda. Journal of Nursing Management, 19 (6), 760-768.

[57] Sungu, L. J., Weng, Q. D., \& Kitule, J. A. (2019). When organizational support yields both performance and satisfaction. Personnel Review, 48 (6), 1410-1428. 